\title{
¿Peregrinación, turismo o turismo religioso? \\ La reinterpretación del Santuario del Señor del Cerrito, Estado de MÉxico
}

\author{
Víctor Manuel Mora Torres \\ Universidad Autónoma del Estado de México \\ victor.mora.torres@gmail.com
}

El presente artículo tiene como objetivo analizar la dinámica social del turismo religioso con respecto a las diferentes interpretaciones que se tienen de la visita al Santuario del Señor del Cerrito, ubicado al norte del Estado de México. El estudio es de corte cualitativo basado en el método etnográfico. Para recabar la información de campo se utilizaron el diario de campo y las entrevistas semiestructuradas a los visitantes. De manera general, se reconocen dos interpretaciones en torno al santuario: como un espacio sagrado y como un espacio recreativo. Se concluye señalando la relación del turismo religioso con la reinterpretación de los espacios sagrados en espacios recreativos.

Palabras clave: Señor del Cerrito, turismo religioso, peregrinación, santuario, interpretación.

\section{Pilgrimage, Tourism or Religious Tourism? Reinterpretation of Sanctuary of the Lord of the Hill, State of Mexico}

The aim of this article is to analyze the social dynamics of religious tourism with regard to different interpretations of the visit to the Sanctuary of the Lord of the Hill, located in the north of the State of Mexico. The study is qualitative, based on the ethnographic method; the field notes and semi-structured interviews to the visitors were used to collect field information. In general, two interpretations are recognized around the sanctuary: as a sacred space and as a recreational space. It concludes by pointing out the relationship of religious tourism with the reinterpretation of sacred spaces within recreational spaces.

Keywords: Lord of the Hill, religious tourism, pilgrimage, sanctuary, interpretation.

Fecha de recepción: 6 de octubre de 2017. Fecha de aceptación: 27 de noviembre de 2017

CÓMO CITAR: Mora, V. M. (2018). ¿Peregrinación, turismo o turismo religioso? La reinterpretación del Santuario del Señor del Cerrito, Estado de México. Dimensiones Turísticas, 2(2), 103-122. https://doi.org/10.47557/QDMV6468 
U na de las formas de movilidad humana más antiguas que perdura hasta nuestros días es la peregrinación. Dentro de las prácticas más comunes en casi todas las religiones se encuentra la visita a espacios considerados como más sagrados o saludables que el entorno de la vida cotidiana (Margry, 2008). Como todo viaje, la peregrinación puede variar en magnitud y distancia, yendo desde desplazamientos cortos hacia las afueras del lugar de residencia hasta viajes de varios días hacia el extranjero. Debido a su naturaleza, la peregrinación es frecuentemente relacionada con el turismo, puesto que ambos implican una salida del lugar de residencia hacia un entorno cualitativamente diferente. Si bien algunos autores consideran a las peregrinaciones como el antecedente directo del turismo (Esteve, 2002; Collins-Kreiner y Gatrell, 2006), el surgimiento del turismo en su forma convencional casi siempre ha sido asociado con la industrialización y las nuevas condiciones laborales que prevalecen desde el siglo xIx (Osorio, 2010).

El origen del turismo y la peregrinación brinda una perspectiva diferente para su comparación en contraste con las similitudes visibles entre estas formas de viaje. Desde la perspectiva de las motivaciones y significados del viaje, el turismo y la peregrinación se contraponen, puesto que ambos se encuentran ligados a conceptos diferentes que orientan la visita: lo sagrado (para la peregrinación) y lo recreativo (para el turismo). En la literatura turística sobre el tema, el peregrino es visualizado como un individuo que se desplaza para estar en contacto con algún tipo de orden sobrenatural, mientras que el turista suele buscar el placer y la relajación (Smith, 1992) en un ámbito diferente al entorno cotidiano.

La relación del turismo con la peregrinación ha sido estudiada en la investigación turística, tal y como lo dejan ver las revisiones llevadas a cabo por Olsen y Timothy (2006), Sharpley (2009) y Tobón y Tobón (2013). Esta relación está generalmente representada por el concepto de turismo religioso, siendo un término más general que engloba manifestaciones tanto del turismo como de la peregrinación. Los trabajos sobre el tema se han concentrado tanto en reflexiones teóricas sobre el significado del turismo y la peregrinación, como en el análisis de patrones de viaje en lugares específicos donde convergen estos dos tipos de movilidades. Lo anterior debido a que "los lugares sagrados se han transformado en puntos de encuentro de visitantes, movidos por la peregrinación, la búsqueda de experiencias religiosas, apreciación del lugar como espacio en sí y su significado cultural; así como por la curiosidad hacia lo sagrado" (Cànoves, 2006, p.68).

En el contexto mexicano, existe un gran número de santuarios que se destacan por la variedad de manifestaciones religiosas que albergan, las cuales constituyen un rico patrimonio cultural que atrae la atención de diferentes visitantes. Gran parte de ellos se interesan en conocer dichos destinos al margen del culto y la adoración, les interesa sobre todo ponerse en contacto con realidades diferentes a las que viven en su entorno cotidiano y que resultan novedosas. Esto es recurrente sobre todo en santuarios donde el catolicismo tradicional se mezcla con los cultos prehispánicos, dando lugar a tradiciones con valor cultural significativo. Muchos de estos sitios pasan desapercibidos en los estudios sobre turismo religioso, debido a que no presentan una gran afluencia de visitantes, si se comparan con otros santuarios como la Basílica de Guadalupe (Carmona, 2012) o la catedral de 
San Juan de los Lagos (Puebla, 2011). Sin embargo, representan un escenario fértil para el análisis de las convergencias entre el turismo y la peregrinación en un mismo sitio.

En tal sentido el presente artículo tiene como objetivo analizar la dinámica social del turismo religioso con respecto a las diferentes interpretaciones que se tiene de la visita hacia los santuarios. En este caso se estudia el Santuario del Señor del Cerrito, ubicado en Jiquipilco, al norte del Estado de México. Este es un lugar de gran valor histórico y cultural ubicado en la cima de una montaña, al que acuden desde tiempos coloniales peregrinaciones de las etnias mazahua y otomí (De la Cruz, 2010). También, a lo largo de todo el año pero principalmente durante sus festividades, el santuario es visitado por un sinnúmero de individuos que no arriban en peregrinación. De esta manera, poco a poco al Santuario del Señor del Cerrito se le ha reconocido como un espacio receptor de personas cuyas motivaciones van más allá de las religiosas tradicionales; razón por la que se le considera un objeto de estudio relevante para el análisis del turismo religioso en lugares considerados como sagrados en primera instancia. El artículo se organiza en cuatro apartados. En el primero se da cuenta de las principales investigaciones que tiene como objeto de estudio la relación entre turismo y peregrinación como una forma de expresión del turismo religioso. En el segundo, se presenta el referente teórico, retomando la noción de centro y las interpretaciones que este puede tener con respecto al turismo y a la peregrinación, asimismo se refieren las consideraciones metodológicas. En el tercero, se detallan los principales hallazgos del trabajo de campo con respecto a las diferentes actividades que se realizan durante la visita hacia el Santuario del Señor del Cerrito. En el cuarto apartado se presenta el análisis de las interpretaciones del santuario en el contexto del turismo religioso con base en los hallazgos del trabajo de campo. Asimismo, se incluyen algunas conclusiones sobre el redimensionamiento del concepto de turismo religioso y la reinterpretación de los espacios sagrados en espacios recreativos.

\section{Breve acercamiento al turismo Religioso}

Puesto que hasta antes de la década de los 70s del siglo pasado predominaba una escasa relación y tratamiento comparativo entre el turismo y la peregrinación en la producción científica internacional, se considera esta fecha como el inicio del abordaje de ambas formas de movilidad de manera conjunta, especialmente en la literatura turística (CoIlins-Kreiner, 2010). Ciertamente tanto el turismo como la peregrinación habían sido estudiadas anteriormente desde diferentes disciplinas, por lo que poseen una vasta tradición científica que explica sus supuestos principales tanto en la investigación en idioma inglés como en español. No obstante, para el caso de esta investigación, interesa conocer las aportaciones científicas que se han hecho sobre estos dos tipos de desplazamiento en conjunto, lo que permite analizar al turismo religioso como una intersección de ambos.

Las propuestas teóricas enmarcadas en la sociología y la antropología, las cuales en su mayoría retoman el carácter sagrado y recreativo de la peregrinación y el turismo respectivamente para establecer convergencias entre ellos, fueron los primeros abordajes 
conjuntos del turismo y la peregrinación. Destacan las propuestas de MacCannell (1973), Graburn (1977) y Cohen (1979). De acuerdo con MacCannell (1973) la conexión entre los viajes turísticos y las peregrinaciones religiosas no solo se refiere a similitudes de organización, puesto que el motivo detrás de una peregrinación es similar al de un viaje turístico: ambos son búsquedas de experiencias auténticas. Los turistas se encuentran en una constante búsqueda de autenticidad, siendo esta una versión moderna del interés universal por lo sagrado. Así el turista se convierte en un peregrino moderno que busca autenticidad en otros "tiempos" y "lugares" fuera de la vida cotidiana.

En una analogía similar, Graburn (1977) afirma que las vacaciones son el equivalente moderno para las sociedades seculares de las festividades anuales para las sociedades religiosas tradicionales. En su propuesta, se contrasta el estado de trabajo ordinario/obligatorio vivido "en casa" y el estado sagrado no-ordinario/voluntario "fuera de casa". El periodo profano es la vida cotidiana, lo ordinario e inevitable; mientras que el tiempo de vacaciones y el turismo es donde la vida es más "real” que la vida real, una vida que vale la pena vivir. Por otro lado, Cohen (1979) propone una tipología fenomenológica que explica las diferentes experiencias turísticas con base en el lugar y significado del turismo en la vida del hombre moderno. Las cinco experiencias que propone son la recreativa, la de distracción, la experiencial, la experimental y la existencial, las cuales representan una serie de combinaciones que van del turismo (recreativa) a la peregrinación (existencial).

Ya que las aportaciones teóricas de esta primera etapa han servido de base para la realización de estudios empíricos posteriores, actualmente continúan considerándose como pilares fundamentales de la llamada "sociología del turismo", dada su generalidad y capacidad explicativa. La década de los 90s aportó nuevos acercamientos hacia el vínculo turismo-peregrinación, en cuanto a la investigación en turismo se refiere. En 1992, se publicó el volumen 19 del Annals of Tourism Research, dedicado en parte al estudio de esta temática. Los trabajos de Smith (1992), Rinschede (1992), Nolan y Nolan (1992), Cohen (1992) y Eade (1992) destacan por sus aportes teóricos. Smith (1992) propone un continuo en el que sitúa a la peregrinación en un extremo y al turismo en el otro, atribuyendo un carácter sagrado a la primera y secular al segundo. "Entre las extremidades subyacen diversas combinaciones entre lo sagrado y lo secular, con un área central comúnmente denominada turismo religioso. Dicha posición refleja las múltiples y cambiantes motivaciones del viajero, cuyos intereses y actividades pueden moverse del turista al peregrino y viceversa" (Smith, 1992, p. 4).

Una tipología de turismo y usos turísticos de los sitios de peregrinación, enfocándose en las características y patrones de viaje de los turistas motivados religiosamente, es la principal aportación de Rinschede (1992). Desde esta lógica existen básicamente dos formas de turismo religioso: "el de corto plazo, que se caracteriza por excursiones a centros de peregrinación o conferencias religiosas cercanas; y el de largo plazo, refiriéndose a visitas de varios días o semanas a sitios de peregrinación o conferencias religiosas nacionales e internacionales" (Rinschede, 1992, p. 51). Por otra parte, el estudio de Nolan y Nolan (1992) se interesa por los sitios religiosos desde una perspectiva turística, estableciendo 
tres tipos de santuarios, acorde al potencial que tienen para atraer visitantes distintos a los peregrinos tradicionales. El primero de ellos se refiere a los santuarios con un fuerte énfasis en la devoción religiosa, pero con pocas características para atraer turistas seculares; el segundo abarca los santuarios que funcionan como centros de devoción y atractivos turísticos, debido a una combinación de características históricas, artísticas y escénicas; mientras que el tercero comprende aquellos lugares donde los festivales religiosos son la principal atracción.

En la década de los 90s se inicia con el estudio de casos específicos para abordar el vínculo turismo-peregrinación. Como ejemplo se tienen el análisis de Cohen (1992) sobre cuatro tipos de templos budistas en Tailandia retomando los postulados teóricos de Turner y Turner (1978). El estudio señala que el peregrino tiende a convertirse en un "peregrino turista" cuando el templo se encuentra más alejado de su hogar, lo que contraviene la idea sobre el aumento del carácter religioso al visitar un templo excéntrico al entorno cotidiano. Asimismo, Eade (1992) aborda el caso de Lourdes, Francia, observando que los peregrinos participan en actividades típicamente turísticas, se visten como turistas, hacen compras similares, y no pueden ser diferenciados de sus contrapartes turísticas en la manera en cómo se relajan de noche. Las propuestas de esta segunda etapa muestran un mayor vínculo entre la teoría y la realidad. Se deja ver que los esquemas y tipologías son aplicables solo en determinados casos puesto que es poco probable construir una teoría general que explique la relación del turismo y la peregrinación debido a lo multifacético del fenómeno.

En un tercer momento de la investigación sobre el tema, surgen estudios empíricos que destacan la existencia de dos grandes grupos de visitantes: los primeros con una motivación de viaje eminentemente religiosa y/o espiritual y los segundos cuyas diversas motivaciones son diferentes a la primera. Entre ellos se puede referir la escala de Collins Kreiner y Kliot (2000), que destaca la creciente convergencia de la peregrinación tradicional y el turismo en sitios sagrados de Tierra Santa; y el estudio de Sharpley y Sundaram (2005) sobre las motivaciones y experiencias de los turistas occidentales que visitan el Sri Aurobindo Ashram en India, identificando a los turistas permanentes y a los visitantes temporales como principales grupos de visitantes. Otros estudios de este tipo son el de Colllins-Kreiner y Gatrell (2006), sobre la experiencia de los visitantes que arriban a los Jardines Bahá'i en Haifa, Israel; y el de Williams, Francis, Robbins y Annis (2006), sobre la experiencia de los visitantes con respecto a la catedral de Gales.

Posteriormente se aprecia una diversificación en la investigación sobre turismo religioso mediante el abordaje de la relación entre turismo y peregrinación desde diferentes disciplinas. Las obras Tourism, Religion and Spiritual Journeys, editado por Timothy y Olsen (2006) y Religious Tourism and Pilgrimage Management: An International Perspective, de Raj y Morphet (2007) son prueba de ello. En la primera, se da cuenta de los principales paradigmas, conceptos y prácticas existentes relacionados a la peregrinación y otras formas de viajes religiosos, desde perspectivas como la naturaleza, creación y gestión de lugares sagrados; la dicotomía turista-peregrino, la economía del turismo religioso y las implicaciones educativas del turismo religioso. En la segunda, se abordan puntos clave en 
estudios de caso contemporáneos sobre la peregrinación religiosa relacionada con destinos turísticos y nuevas formas de peregrinación; sus bases teóricas provienen del turismo, los eventos, la economía, la sociología, la psicología y la teoría cultural, así como diferentes tradiciones culturales y filosóficas de Oriente y Occidente.

Los estudios en español sobre turismo religioso se desarrollan principalmente en España y México a partir del nuevo milenio. Las investigaciones incorporan elementos conceptuales de la economía y la administración para explicar realidades del turismo religioso o proponer el desarrollo de productos turísticos. Se resalta la visión de lugares sagrados como recursos susceptibles de aprovechamiento para la generación de ingresos. Este tipo de investigaciones puede incluir aquellas que muestran los beneficios económicos de las peregrinaciones y el turismo para las comunidades que albergan a los santuarios, como la de Puebla (2011), sobre San Juan de los Lagos, México; estudios que analizan la satisfacción de los visitantes, como el de Millán, Morales y Pérez (2010) con respecto a las rutas del Camino de Santiago; o bien aquellos que enfatizan el potencial turístico del patrimonio religioso, como el de Cànoves y Blanco (2011).De igual manera, la investigación en idioma español se ha caracterizado por la realización de trabajos mayoritariamente empíricos, dejando en segundo término la generación de marcos teóricos y conceptuales para el turismo religioso. Los artículos de Cànoves (2006), Maak (2009) y Hruleva, Blanco y Cànoves (2013), que "abordan el aprovechamiento de diferentes sitios y rutas religiosas en Europa como parte de proyectos de desarrollo turístico que generen beneficios económicos a las comunidades" (Mora, Serrano y Osorio, 2017, p. 94) que habitan estos sitios, son ejemplo de ello. Cebrián y García (2014) presentan el "diseño de una ruta de santuarios al sureste de España aplicando los criterios de centralidad y significado de las visitas religiosas" (Mora, Serrano y Osorio, 2017, p. 96), mientras que Lorenzo y Ramón (2011) estudian "la fiesta en honor al Santísimo Misterio de los Corporales, en Lluxent, España para una posterior puesta en valor de su ruta” (Mora, Serrano y Osorio, 2017, p. 96). En México, Fernández (2012) revisa la actual relación entre Iglesia, Estado y sociedad con respecto al santuario de la Virgen de Talpa. Jalisco.

Tal y como lo deja ver este breve acercamiento, el estudio del turismo religioso, entendido como el análisis de las convergencias entre el turismo y la peregrinación, ha evolucionado desde propuestas generales y teóricas hasta el abordaje de casos específicos y el diseño de productos turísticos en los que se involucran rutas y santuarios. Se han incorporado elementos de diversas disciplinas al análisis de realidades tan variadas como las mismas manifestaciones religiosas. No obstante, existe aún una carencia de conocimiento con respecto a cómo se presenta la relación del turismo con la peregrinación en lugares inicialmente considerados como santuarios, pero que actualmente muestran indicios de actividad turística. Al respecto en el siguiente apartado se realiza una reflexión sobre cómo algunos postulados teóricos del turismo religioso permiten la comprensión de dicha relación. 


\section{Turismo religioso ¿entre el turismo y La PeRegrinación?}

Dentro de los aspectos abordados en la investigación sobre turismo y peregrinación se encuentran las coincidencias y diferencias entre el peregrino y el turista. Dichos tipos de viajeros son diferentes con respecto a las motivaciones de su desplazamiento: a los primeros los mueven profundas convicciones religiosas y espirituales, mientras que los segundos viajan por placer, educación, curiosidad, altruismo o la relajación (Olsen y Timothy, 2006). Las características asociadas a estos tipos de viajeros también son diferentes El peregrino tiende a ser pío, humilde y sensible con la cultura receptora, en contraste con el turista, quién parece ser hedonista y cada vez más exigente en términos de servicios, necesidades y deseos en el destino (de Sousa, 1993; Gupta, 1999). Esta visión de turista y peregrino tiene sus bases en los significados tradicionales asociados al turismo y a la peregrinación como formas de viaje.

De acuerdo con Margry (2008), la peregrinación es un complejo de comportamientos y rituales en el dominio de lo sagrado y lo trascendente, en el que la religión y las personas religiosas se muestran en una forma poderosa y colectiva. La finalidad del viaje es la búsqueda de un encuentro trascendental con un objeto de culto específico, con el propósito de adquirir beneficios espirituales, emocionales o de curación física. Asimismo, la peregrinación puede ser "una experiencia social de movimiento y transición en la que los individuos voluntariamente abandonan las estructuras y patrones de la vida social normal y emprenden un viaje extraordinario por un paisaje sacro" (Turner y Turner en Shadow y Rodríguez, 1994, p. 28). Turner y Turner (1978), indican que en la peregrinación se percibe una sensación liberadora de comunalidad, universalismo y fraternidad entre quienes viajan, cuyas relaciones son igualitarias, no diferenciadas, directas, no racionales y existenciales.

El turismo, en cambio, es una consecuencia de las civilizaciones industriales, "un fenómeno social derivado de otro fenómeno social: el tiempo libre institucionalizado" (Boullón, 1983: 89). En la ruptura del tiempo de trabajo para dar paso al tiempo libre es donde gran parte de la investigación sobre turismo ubica este fenómeno, asumiendo que se aprovecha dicho periodo de tiempo para viajar. No obstante, para que un viaje se considere como turístico debe cumplir con otras características. Para Osorio (2005), el viaje turístico, además de realizarse fuera del tiempo de trabajo (en el llamado tiempo libre), debe llevarse a cabo fuera del entorno cotidiano y tener al ocio como principal motivador. El ocio turístico, entendido como lo realizado durante el tiempo libre, conlleva una serie de actividades elegidas libremente que implican un escape de la cotidianidad (Lanquar, 1985; Azevedo y Gomes, 2013). Este, junto con la recreación, son los motivos principales por los que los individuos emprenden un viaje turístico.

Sin embargo, ya que en la actualidad muchos santuarios no son lugares exclusivos de culto sino también espacios de visita, resulta complicado separar las motivaciones de los visitantes, donde se mezclan los auténticos peregrinos, que visitan el lugar movidos por la fe; los turistas, que aprovechan la visita para acercarse al lugar religioso; y los turistas que visitan el lugar con una motivación patrimonial y cultural, al margen del hecho religioso (Cànoves y Blanco, 2011). Puesto que "las dicotomías rígidas entre la peregrinación y el 
turismo o los peregrinos y los turistas ya no parecen defendibles por mucho tiempo" (Badone y Roseman, 2004:2), algunos investigadores destacan la necesidad de conciliar la otrora polaridad del turismo con la peregrinación mediante fundamentos teóricos que expliquen su coexistencia en sitios religiosos (Badone y Roseman, 2004, Collins-Kreiner, 2010).

Al respecto, el concepto de turismo religioso propuesto por Smith (1992) resulta útil para cumplir con dicho propósito. De acuerdo con la autora, el turismo religioso es una posición que refleja las motivaciones múltiples y cambiantes del viajero, cuyos intereses y actividades se mueven de las del turista al peregrino y viceversa, incluso sin ser conscientes del cambio. Es decir, el turismo religioso pasa a ser un espacio teórico de coexistencia entre el turismo y la peregrinación, en lugar de una más de las modalidades turísticas asociada con el consumo de productos culturales-religiosos. El turismo religioso ocupa un espacio único en el imaginario de los viajes religiosos y seculares, lo algunos investigadores denominan como "tercer espacio". Al percibir a los lugares religiosos como un "tercer espacio", los investigadores tienen la posibilidad de deconstruir las prácticas sociales de los turistas en los sitios religiosos, evitando las nociones simplificadas de "viajero religioso" o "vacacionista" como peregrino y turista respectivamente. Este enfoque revisado para el turismo religioso, basado en parte en el concepto de "tercer espacio" reconoce, tanto implícita como explícitamente el carácter interdependiente de los dos actores y la construcción social de un sitio que es a la vez sagrado y secular (Collins-Kreiner y Gatrell, 2006).

Para explicar las diferentes interpretaciones que se puede dar al espacio, en este artículo se retoma la propuesta de Cohen (1979), la cual forma parte de la formulación de su tipología sobre la experiencia turística. De acuerdo con el autor, el elemento principal que permite dicha interpretación es la dirección del viaje. El lugar y el significado del turismo en la vida del hombre moderno se derivan de su visión total del mundo y dependen especialmente de la cuestión de si se adhiere o no a un "centro", y de la localización de este "centro" en relación con la sociedad en la que vive. El centro representa el nexo carismático de una sociedad con sus valores morales supremos y fundamentales, y que no es necesariamente central geográficamente en la vida de una comunidad.

Generalmente las religiones tienen centros sagrados que las personas desean visitar, ya que para el hombre religioso el espacio no es uniforme. Los diferentes lugares pueden considerarse como espacios sagrados o espacios no sagrados (Eliade, 1998). El espacio sagrado puede considerarse como un lugar donde se manifiesta una realidad que no pertenece a este mundo en objetos que forman parte del mundo natural o profano, siendo este estado la "realidad por excelencia" (Eliade, 1998). Los objetos que poseen el carácter sagrado dentro de la realidad son consideradas como superiores en deidad y poder con respecto a las cosas profanas, un medio ideal y trascendente que se opone al mundo material (Durkheim, 2000). En muchas sociedades, la necesidad de estar en contacto con el centro origina ciertos desplazamientos hacia el espacio sagrado.

Puesto que el centro no necesariamente se ubica dentro del espacio de residencia de los creyentes, su localización externa orienta a la peregrinación como un viaje sagrado de ascensión espiritual (Turner, 1973). En el caso de la peregrinación tradicional, el centro 
está localizado dentro del "mundo" del peregrino, pero más allá de las fronteras de su espacio de vida inmediato; esta contingencia se afirma sobre una separación entre el espacio de vida limitado y su "mundo": la imagen de este último es más extensa y abarca un gran número de espacios de las comunidades individuales o de las sociedades. La peregrinación es esencialmente un movimiento de la periferia profana hacia el centro religioso o “cosmos" religioso (Cohen, 1979). Lo profano, refiriéndose al entorno cotidiano que se percibe como ajeno al santuario, es considerado un lugar que desgasta al ser humano y a la sociedad.

En cambio, desde una perspectiva turística, se asume que el centro del hombre moderno se localiza dentro de los confines de su sociedad, es decir, él se "alineará" con los valores fundamentales del lugar donde reside. Dicha conformidad puede generar tensiones e insatisfacciones que el individuo aliviará a través del turismo, el cual es una forma de entrada temporal a un centro, pero en relación con la biografía individual, su plan de vida y aspiraciones, permanece en un significado periférico. El turismo solo es funcional mientras no se convierta en algo central dentro del plan de vida y aspiraciones del individuo, en tanto regule sus tensiones e insatisfacciones, refrescándolo y restaurándolo, sin destruir su motivación para desempeñar las tareas de la vida cotidiana. El turismo masivo moderno es asumido sobre un desarrollo diferente al de la peregrinación: el abandono gradual de la imagen sagrada y tradicional del cosmos, y el despertar del interés por la cultura, vida social y entorno natural de otros (Cohen, 1979).

Las peregrinaciones y el turismo moderno, se asumen en concepciones sociales diferentes del espacio y visiones contrarias referentes al tipo de destinos que vale la pena visitar y de su localización en el espacio socialmente construido; de ahí que implican movimientos en direcciones opuestas: en la peregrinación de la periferia (que en este caso sería el lugar de residencia del peregrino) hacia el centro de su cultura (el santuario a visitar), y en el turismo moderno, del centro cultural (su lugar de residencia, el ámbito de la vida cotidiana) hacia la periferia (en este caso, el destino religioso). Sin embargo, ante la presencia simultánea de actividades comúnmente asociadas al turismo y a la peregrinación en diferentes santuarios, se hace necesario conocer cuál es la interpretación que les individuos asignan al espacio visitado, lo que explicaría el sentido de dichas actividades y la coexistencia del turismo con la peregrinación en un mismo sitio.

En el presente artículo se abordan las interpretaciones que, desde la perspectiva de la visita, se generan entorno al Santuario del Señor del Cerrito, lugar ubicado en una comunidad rural perteneciente al Estado de México. El análisis se centra en la peregrinación que parte de San Pedro Cholula, en Ocoyacac, Estado de México, hacia el santuario para asistir a la Fiesta del Señor del Cerrito, realizada el 3 de mayo de cada año. En consonancia con el enfoque interpretativo del referente teórico, el estudio es de corte cualitativo, y se apoya en el método etnográfico. Para obtener la información de campo necesaria, el investigador participó en la peregrinación en su edición 2014. Se llevó a cabo observación directa y participante, la información obtenida se registró en un diario de campo. Asimismo, se aplicaron 20 entrevistas semi-estructuradas a personas que participaron en el viaje. 
Posteriormente se procedió a realizar un análisis de contenido de la información obtenida, de manera que pudieran reconocerse tendencias generales sobre las interpretaciones en torno al espacio visitado con base en el referente teórico. A continuación se exponen los principales hallazgos del trabajo de campo.

\section{La visita al Santuario del Señor del Cerrito}

El Cerrito de Tepexpan es una elevación de 3009 metros, localizado en la comunidad de Santa Cruz Tepexpan, perteneciente al municipio de Jiquipilco, al norte del Estado de México. En la cima, se ubica un santuario de estilo barroco en su interior y neoclásico en su exterior, el santuario resguarda la imagen de un cristo conocido como el Señor del Cerrito. Se refiere que "el Santuario del Cerro de Tepexpan es el segundo más visitado en la región del Valle de Toluca, después del Santuario del Señor de Chalma (Hernández, 2013:1)”, debido a las peregrinaciones mayoritariamente indígenas, que tradicionalmente acuden a las diferentes celebraciones. Principalmente dos grupos indígenas son los que visitan desde antaño el Cerrito de Tepexpan: los mazahuas y los otomíes. Estos grupos han habitado, desde tiempos ancestrales, el territorio de diversos municipios que forman parte del actual Estado de México (Barrientos, 2004a). De ahí que el Cerrito de Tepexpan sea un punto geográfico sobresaliente que los mazahuas y otomíes han significado a partir de sus prácticas ceremoniales (Barrientos, 2004b).

Las principales festividades en ocasión de las cuales se llevan a cabo peregrinaciones hacia el santuario son la del 3 de mayo, en honor al Señor del Cerrito, y la del 15 de octubre, en honor a Santa Teresa de Jesús (De la Cruz, 2010). El viaje puede durar desde dos hasta siete días dependiendo del lugar de origen de las peregrinaciones. Algunos municipios de donde provienen las peregrinaciones son Almoloya de Juárez, Temascalcingo, Almoloya del Río, Ixtlahuaca, Ocoyoacac, Huixquilucan, Lerma y Santiago Tianguistenco, ubicados en el Estado de México (Hernández, 2013). Quienes participan en las peregrinaciones juegan un papel clave en la realización de las festividades, ya que la mayoría de quienes participan en la celebración son personas ajenas a Santa Cruz Tepexpan.

La organización de cada peregrinación está a cargo de la mayordomía. Esta podría definirse como un grupo de personas originarias de una misma localidad, a quienes se les encomienda la planeación y correcto desarrollo de la peregrinación durante la ida, la estancia en el santuario y el regreso. Los mayordomos son los organizadores y coordinadores de la peregrinación, destacan por su buena reputación ante la comunidad de feligreses católicos, siendo llamados por el resto de los viajeros y por los otros mayordomos como "compadritos" y "comadritas". La mayordomía de la peregrinación de San Pedro se renueva cada tres años, siendo el santuario del Señor del Cerrito el lugar donde los nuevos mayordomos adquieren el compromiso organizar y coordinar la peregrinación. Entre las labores de los mayordomos se encuentran: conseguir el transporte de apoyo durante el recorrido, gestionar los lugares de hospedaje, invitar con anticipación a los miembros de la 
comunidad católica a participar en la peregrinación, cuidar a los miembros de la peregrinación mientras van caminando, coordinar el tráfico cuando la peregrinación viaja por carretera, en los lugares de pernocta deben vigilar que haya orden durante la noche, y durante el viaje proveer de alimentos y bebidas a todos los participantes del viaje.

Existen seis objetos sagrados que son fundamentales en la peregrinación. Los más importantes son las réplicas en miniatura de San Pedro y la del Señor del Cerrito. Los otros cuatro objetos sagrados son: una alcancía, que es un recipiente donde se guarda la limosna o dinero aportado por los creyentes; una charola o bandeja que se utiliza para servir comida y/o bebidas; una campana y un petate, tapete pequeño elaborado con palma. Los objetos pueden ser cargados por personas de la comunidad. En el camino rumbo al santuario, los visitantes realizan algunas paradas, las cuales implican periodos de tiempo dedicados al descanso y la convivencia. Los lugares donde la peregrinación realiza las paradas han sido definidos desde tiempo atrás y no hay descansos en zonas diferentes a las tradicionales. Los puntos específicos en donde se hacen las paradas, particularmente cuando la peregrinación camina por campo abierto, se identifican por una pequeña construcción de color blanco y una cruz a lado.

La última parada antes de llegar al santuario es de suma importancia, pues en este lugar se lleva a cabo el cambio de mayordomía. Los mayordomos salientes hacen entrega a los nuevos mayordomos de los objetos sagrados de la peregrinación. A las 7 de la mañana del 3 de mayo, se lleva a cabo la ceremonia religiosa de bienvenida a las peregrinaciones en la iglesia del Cerrito, donde los mayordomos entrantes se oficializan en el cargo, haciendo un juramento para cumplir a cabalidad la misión que se les ha encomendado.

A lo largo del trayecto los viajeros cuentan historias y creencias relacionadas con los santos, se dice, por ejemplo, que el Señor del Cerrito ayuda a algunos miembros de la comunidad a recuperar la salud. En caso de que los visitantes se comporten inapropiadamente en el Cerrito son castigados. Al respecto hay un relato acerca de una pareja de peregrinos que tuvo un acto pasional cerca del santuario, por lo que fueron convertidos en una roca, imagen que representa a "Los Compadres". Durante el viaje, se da muestra de fe al tratar de no quejarse por el esfuerzo físico que hace, se cree que las personas que se quejan se cansan más rápido, pueden caer o encontrarse con animales peligrosos en el camino. Quienes visitan el santuario por primera vez deben entrar de rodillas hasta el altar, y de no seguir la costumbre pueden sufrir "mal de montaña" (náuseas y dolor de cabeza).

Al llegar al pie del Cerrito, las personas inician el ascenso para alcanzar la cima, que es donde se encuentra el santuario y la imagen del Señor del Cerrito. Esta parte es visualizada como la más retadora de todo el trayecto al ser un camino inclinado en razón de la elevación del terreno. Al ascender al santuario, las personas tienen por costumbre hacerse “limpias" para aliviar el cansancio, esto es, se frotan todo el cuerpo con ramas de plantas o árboles y una pequeña piedra, sobre todo en las partes donde sienten mayor molestia física. Esta actividad se lleva a cabo frente a las cruces o árboles que son muy significativos y se encuentran a lo largo del camino. No todos los que visitan el santuario participan en las "limpias", algunas personas solo se detienen para observar el paisaje o apreciar 
los rituales. Otras prefieren apresurar el paso para llegar antes que aquellas que caminan lentamente.

Alcanzada la cima, los viajeros ingresan al santuario para estar en presencia del Cristo. Como muestra de sacrificio y agradecimiento, algunos de ellos apoyados en sus rodillas recorren el espacio que va desde la entrada hasta el altar. Durante el 3 de mayo se celebran ceremonias religiosas en honor al Cristo. En el interior del santuario destacan las ofrendas al Señor del Cerrito, entre las principales se encuentran veladoras, listones, ramas de árbol, semillas y prendas de vestir. Una vez fuera del templo, los visitantes buscan un lugar donde comer. Una vez elegida el área, se reúnen para hacer una fogata y calentar sus alimentos, también pueden pedir de favor que les permitan calentarlos en las cocinas que hay para tal fin. Otra opción es comprar sus alimentos y bebidas en los puestos establecidos en la explanada; la oferta aproximada es de 25 locales y puestos.

El tiempo de comida es también un tiempo de convivencia. El consumo de bebidas alcohólicas, principalmente entre jóvenes y adultos jóvenes, está estrechamente relacionado con la recreación y el disfrute de la ocasión. Para recordar la experiencia, algunas personas compran determinados objetos, estos pueden estar ligados al aspecto religioso, como los rosarios, cuadros o imágenes de santos, crucifijos, entre otros; o ser artesanías como los juguetes de madera, bordados y cestería. Gran parte de los visitantes compra fotografías que dan evidencia de los diferentes momentos de su experiencia de viaje.

Las danzas que se presentan en la explanada frente a la iglesia atraen la atención de gran parte de los asistentes, quienes se congregan alrededor de los danzantes para apreciar y tomar fotografías. En el caso de la peregrinación de San Pedro Cholula, la danza tradicional del pueblo (Danza de los Arrieros) acude al santuario el día de la fiesta del 3 de mayo como parte de los rituales en honor al santo. La indumentaria y pasos son elementos visuales muy atractivos que es posible que no puedan observarse en otras fiestas religiosas. De igual manera, quienes visitan el santuario en ocasión de la festividad se muestran atraídos por el paisaje natural que rodea al templo, especialmente por la vista desde la cima del valle de Ixtlahuaca. Las caminatas por los senderos cercanos al santuario para conocer la capilla de Santa Teresa o el manantial que se encuentra en la cima son recurrentes.

Las actividades mencionadas muestran una naturaleza bivalente del santuario, no solo como un lugar de manifestaciones religiosas sino también como un espacio donde se llevan a cabo actividades más cercanas al turismo. Es a partir de las peregrinaciones tradicionales que parece surgir el turismo, y con ello, una reinterpretación del santuario a partir de la visita. A continuación se describen las principales interpretaciones que se entretejen entorno al Santuario del Señor del Cerrito.

\section{Interpretaciones del Santuario del Señor del Cerrito a partir de la visita}

Si se considera que a partir de las peregrinaciones tradicionales surge la actividad turística en el Santuario del Señor del Cerrito, es posible reconocer diversas interpretaciones del santuario a partir de los significados preponderantes que pueden asignar los mismos 
visitantes a sus actividades durante la visita. En este sentido, se aprecia la coexistencia de dos formas principales de interpretar el santuario: el viaje como búsqueda de lo sagrado y el viaje como búsqueda de recreación.

\subsection{El santuario como espacio sagrado}

Esta interpretación es predominante entre los visitantes asiduos y de mayor edad, asociados a la noción de peregrino tradicional. Estos individuos participan en la peregrinación hacia el santuario con motivo de la fiesta del Señor del Cerrito desde hace varios años. Suelen estar familiarizados con las actividades de la región de donde proceden y con las tradiciones de la religión católica propias de la comunidad. A partir de esta interpretación, el Santuario del Señor del Cerrito no es un lugar más de adoración a Cristo, sino que representa el "centro del mundo", un espacio que alberga una deidad de suma importancia para mantener las condiciones de la vida cotidiana de manera propicia. El cerro, en cuya cima se ubica el santuario, no es más un accidente geográfico, puesto que forma parte de la deidad en sí, siendo una prolongación tangible del poder divino: por eta razón el Cristo es denominado Señor del Cerrito y en algunos cánticos es denominado "Señor de la Montaña". El paisaje del cerro es impregnado con el carácter mágico/milagroso atribuido al Cristo.

Durante el ascenso al santuario, los peregrinos enfatizan el significado del cerro como una extensión del Señor del Cerrito. Lo acontecido en ese espacio sagrado es observado por él, por lo que las conductas inapropiadas son castigadas. Asimismo reconocen que determinados elementos del paisaje poseen un significado especial, en la medida en que les recuerdan el poder y omnipresencia del Cristo en el territorio del cerro; la roca de "Los Compadres" es quizá el ejemplo más representativo. Al ascender por el camino, los peregrinos asumen una actitud de respeto y reverencia, ya que esto significa la penitencia inherente al contacto con lo sagrado, por tanto no se debe renegar a pesar de la fatiga o de cualquier otra dificultad que se les presente a lo largo del camino pedregoso. La naturaleza misma puede obrar en contra de quien contraviene al ser sagrado, ya que de acuerdo con la creencia, a quienes lo hacen les puede aparecer serpientes o sufrir accidentes. El "mal de montaña" se le considera una desgracia que padece el peregrino, cuya conducta ha sido inapropiada, relacionando al castigo con el espacio donde se encuentra el santuario.

Paradójicamente, el carácter milagroso del cerro también está presente en ciertos elementos del paisaje que son benéficos o protegen a quienes terminan el recorrido hasta el santuario, sin quejarse. Cuando el individuo se frota con hojas y piedras del camino para aliviar su molestar, entra en contacto con la divinidad, quien lo renueva con su poder para que pueda continuar ascendiendo hasta llegar a la cima. Las "limpias" se llevan a cabo en puntos clave del ascenso (parajes, cruces y árboles, entre otros) a los que los peregrinos les asignan un significado especial desde hace muchos años; estos puntos no se han cambiado y continúan respetándose como paradas oficiales, en donde se realizan los rituales propios de la peregrinación. Dentro de las peticiones que los peregrinos dirigen al Señor del Cerrito se encuentran aquellas relacionadas con la lluvia y el logro de las cosechas, ofrecen a la deidad elementos del paisaje natural, como ramas de árbol, semillas y el 
esfuerzo de todos aquellos que suben a visitarlo. El paralelismo entre la cruz, como símbolo de Cristo y del Señor del Cerrito, con los árboles y los parajes, apoya la interpretación del santuario como un espacio sagrado, en el que la deidad y el lugar visitado se fusionan en un entorno mágico que orienta la vida caótica de la cotidianidad.

Es de destacar que el cambio de mayordomía en las inmediaciones del Cerrito se significa en este sentido. La mayordomía es un grupo de personas que, de alguna manera, da continuidad al viaje de peregrinación. Dada su connotación religiosa, es necesario que el cambio sea "oficializado" ante la divinidad representada por el entorno. Para tal fin, previo a la llegada al santuario, se hace una pausa en un paraje del cerro, ahí cada mayordomo saliente entrega, a sus contrapartes entrantes, uno de los objetos sagrados. Al entregarse las imágenes de San Pedro y el Señor del Cerrito (santo patrono de la comunidad y santo que se visita, respectivamente), se reafirma de manera simbólica el vínculo entre el espacio sagrado y la vida cotidiana. Es evidente que la mayordomía solo adquiere el estatus correspondiente para llevar a cabo sus labores en el entorno visitado, no se puede llevar a cabo un nombramiento de este tipo en el lugar de residencia, considerado como profano.

Para quien que visita el santuario interpretándolo como un lugar sagrado, es decir, como el centro que orienta su vida cotidiana, la vista del valle de Ixtlahuaca que aprecia desde la cima del cerro es muestra de la magnificencia y bondad de la divinidad. Es posible apreciar desde la cima varias de las comunidades de donde provienen los peregrinos, lo que reafirma la percepción del Cerrito como centro del mundo. Esta noción de centro del mundo define la trascendencia de la visita al santuario para poder continuar el resto del año en el entorno de la vida cotidiana: se espera que este periodo corto fuera de casa pueda tener efectos positivos en el lugar de residencia que aseguren la salud y el sustento.

\subsection{El santuario como espacio recreativo}

Esta interpretación del espacio es común entre los participantes más jóvenes de la peregrinación e incluso en personas que acuden a la festividad pero no viajan en peregrinación. Quienes asumen esta interpretación suelen interesarse en el viaje por comentarios o invitaciones hechos por personas que anteriormente han visitado el lugar. Dado que estos individuos consideran al entorno de su vida cotidiana como el centro que orientan sus actividades, no prevalece en ellos la visión del santuario como "centro del mundo". El interés por la visita surge a partir de las diferencias que muestra el espacio donde se sitúa el santuario con respecto al de su vida cotidiana. El acudir al santuario implica el contacto con los centros y formas de vida de otras personas, lo cual permite la restauración y/o renovación del individuo para reincorporarse a la realidad constrictiva del entorno cotidiano. Las personas que asumen esta interpretación del santuario suelen estar familiarizadas con los entornos urbanos en su lugar de residencia.

Esta idea cobra sentido a la luz de algunos hallazgos del trabajo de campo, los cuales pueden ser interpretados desde esta lógica. Por ejemplo, la mayordomía, además de ser un grupo de carácter religioso que perpetúa la tradición de la peregrinación, es también 
la organizadora de los aspectos operativos del viaje, principalmente del transporte y el hospedaje. La previsión de estas cuestiones es necesaria puesto que se está entrando en contacto con un entorno "desconocido", en donde hay que asegurar los lugares de descanso, los medios en los que se viajará y las rutas que se seguirán para evitar contratiempos y la insatisfacción del viaje. Se pretende evitar cualquier situación que genere conflicto con respecto al desplazamiento y estancia en el santuario, ya que desde esta interpretación la finalidad de la visita es aliviar las tensiones cotidianas.

Las pausas que se hacen a lo largo de la ruta no solo tienen una finalidad ritual, sino que también propician momentos de convivencia que favorecen el surgimiento o fortalecimiento de las relaciones sociales entre peregrinos. Las conversaciones entre viajeros giran en torno a diferentes situaciones de la vida cotidiana, contribuyendo al desahogo de las tensiones. Dado que este tiempo es diferente al que se experimenta en el lugar de residencia (pues no están sujetos a la dinámica habitual), están en posibilidad de conocer mejor "al otro" con quien viajan. La apreciación del paisaje natural alrededor de las paradas, les permite valorar la tranquilidad de un espacio diferente al cotidiano. Asimismo, se presta atención a las leyendas y creencias relacionadas con el Cristo, las cuales no son asumidas como ciertas o necesarias para el correcto desarrollo del viaje, sino como elementos culturales de interés. Resulta de interés el conocer diversas formas de pensar y concebir el mundo gracias a la tradición oral, pues esto permite la renovación y distracción inherente a la visita.

En este sentido es que estas personas contemplan, e incluso participan, de la festividad y de la peregrinación. Pero sus acciones son interpretadas como manifestaciones culturales externas a ellos, pues desconocen (o no comparten) el significado sagrado que entrañan para los peregrinos más tradicionales. Así, las "limpias”, ofrendas y danzas no representan una forma de comunicación con lo sagrado, sino que despiertan la curiosidad de los visitantes, quienes en su mayoría observan y fotografían lo que para ellos es extraño y novedoso, y en algunos casos se interesan por participar. Esto mismo sucede con la arquitectura del santuario o la vista que se tiene del valle desde la cima del cerro, puesto que se asocia más con elementos que les recuerde su visita al Cerrito, en el sentido de que posiblemente no los puedan encontrar en sus viajes a otros sitios semejantes. Se puede decir que la visita en general tiene un carácter exótico, incluso con respecto a los alimentos y bebidas que se consumen durante el viaje. El degustar ciertos platillos y bebidas propios del contexto contribuye a enriquecer la experiencia cultural de los visitantes.

Puesto que la peregrinación representa una entrada temporal hacia otra realidad, las personas que asumen esta interpretación se relajan y realizan actividades que en su entorno cotidiano no llevarían a cabo de la misma manera. Esto explica por qué durante el viaje y estancia en el santuario es común el consumo de bebidas alcohólicas. Esto forma parte del matiz recreativo del viaje, pese a que en un inicio el desplazamiento era de carácter meramente religioso. Igualmente, al tratarse de una entrada temporal a otra realidad, se busca llevar al entorno cotidiano algún(os) objeto(s) que permitan recordar, en el futuro, la visita al santuario. Algunos de ellos son los recuerdos religiosos, artesanías y fotografías. 
El surgimiento de la actividad comercial durante los días de fiesta responde a los requerimientos de los "nuevos peregrinos", quienes muestran una faceta que se acerca cada vez más al turismo.

Se expresa como positiva la experiencia adquirida al acudir al Santuario del Señor del Cerrito en días de fiesta, en una valoración general sobre la visita. En esta interpretación el visitante puede separar con claridad la visita al Cristo, que le puede representar la parte religiosa del viaje, sin dejar de disfrutar del recorrido por el cerro y de otras actividades con fines recreativos. Por lo que se deduce que la peregrinación y el Santuario del Señor del Cerrito en conjunto con los paisajes del campo, arquitectura religiosa, danzas coloridas, artesanías y alimentos y bebidas tradicionales, hacen de este lugar un espacio recreativo que contribuye por una parte a aliviar las presiones de la vida cotidiana, favoreciendo la reincorporación y alineación del visitante a su entorno una vez que finaliza el viaje, y por otra parte impulsa el desarrollo de actividades comerciales y de servicios propios del turismo.

\section{Conclusiones}

El análisis de la relación entre turismo y peregrinación como un acercamiento entre estas dos formas de viaje no es solo una tendencia en la investigación turística, más bien responde a una realidad presente en muchos espacios considerados como religiosos en un primer momento. Desde hace varios años, se ha presenciado la irrupción del turismo en esferas de la sociedad que habían permanecido aisladas de este fenómeno, como en el caso de las peregrinaciones tradicionales hacia los lugares de culto. Esta ruptura de esferas en otro tiempo claramente definidas da lugar a dinámicas sociales, las cuales no son uniformes sino que tienen peculiaridades con respecto al contexto donde se desarrollan.

En este trabajo se ha pretendido mostrar como el reconocimiento de las diferentes interpretaciones asignadas al espacio permiten comprender la dinámica del turismo religioso en el contexto específico del Santuario del Señor del Cerrito. Si se entiende al turismo religioso como un punto de encuentro entre el turismo y la peregrinación, que se manifiesta en la experiencia de viaje de las personas, entonces es posible comprender como la peregrinación tradicional ha dado lugar al surgimiento del turismo, visible no solo en la oferta de servicios en el santuario sino más bien en la actitud recreativa que asume una parte de los visitantes, ya sea que viajen en peregrinación o no. Así, el santuario ha sido resignificado de acuerdo con una interpretación turística. Asimismo, se aprecia un estrecho vínculo entre el espacio visitado y el de lugar de residencia en ambas interpretaciones pues, a diferencia de otros tipos de viajes, en ambos casos se espera obtener beneficios visibles en la cotidianidad una vez concluida la visita. De ahí que estas formas de concebir al santuario pertenezcan a una sola forma de viajar: el turismo religioso.

En ambas interpretaciones del santuario se reconoce la necesidad de renovar o volver a crear ciertas condiciones en el lugar de residencia mediante la visita, por lo que podría considerarse a la "re-creación", el renovarse, como el elemento unificador y significado primordial que orienta al turismo religioso. En el caso de la interpretación del santuario como 
espacio sagrado, se pretende asegurar principalmente la salud y el sustento mediante la intervención de la divinidad, ya que estas cuestiones escapan a las capacidades humanas. En la interpretación del santuario como espacio recreativo se busca la renovación anímica al entrar en contacto con una realidad que es novedosa e interesante en relación con su lugar de residencia. Es así que la "re-creación", el "volver a crearse", es el fin último de la visita en el turismo religioso, y por tanto el significado primordial que orienta las actividades en el santuario.

El reconocer la existencia de por lo menos dos interpretaciones principales que se entretejen en torno al santuario en el marco del turismo religioso, brinda información importante sobre la dinámica social de esta modalidad, lo cual puede permitir mejorar su gestión en un futuro. Se destaca que para que el santuario pueda seguir considerándose un espacio recreativo es necesario que al mismo tiempo sea interpretado (por otras personas) como un espacio sagrado. El atractivo turístico del espacio que circunda al Santuario del Señor del Cerrito es su carácter mágico, apreciado como cualitativamente diferente a las realidades de donde provienen algunos visitantes. En el futuro se deben de tomar acciones encaminadas a la preservación de ambas interpretaciones, delimitando los espacios donde se lleven a cabo determinadas actividades, fomentando la participación y/o apreciación respetuosa de los rituales y dando a conocer el significado sagrado de lo que observan quienes no asumen una interpretación religiosa. El turismo religioso es una modalidad que permite el enriquecimiento personal en dos vías: por una parte se enriquece el conocimiento de la persona a través de la puesta en contacto con otras formas de vida diferentes a las que le son familiares, y por el otro, se favorece la preservación del patrimonio cultural religioso a través de incentivos económicos derivados de la actividad turística.

Para concluir, se reafirma que el turismo no es un concepto más general que englobe a la peregrinación, así como la incompatibilidad del turismo en su forma convencional con lo que aquí se entiende por turismo religioso. Desde la perspectiva de reinterpretación de los santuarios, el turismo religioso no es una nueva tendencia de los viajes turísticos que se centran en el patrimonio religioso (de hecho es cuestionable su novedad), sino que más bien representa la evolución de la peregrinación como fenómeno social, y por consiguiente, de algunos santuarios. Aquí se propone entender al turismo religioso como un concepto más abarcador, en el que es posible ubicar las diferentes reinterpretaciones de la peregrinación que han surgido (y que continuarán surgiendo) a partir de la intersección de los significados religiosos y recreativos. En ese sentido, la investigación en diferentes lugares debe continuar con la finalidad de mejorar la comprensión sobre la evolución de los santuarios hacia destinos de turismo religioso gracias a la reinterpretación que los visitantes hacen de los mismos. 


\section{REFERENCIAS}

Azevedo, J. y Gomes, C. (2013). El ocio y el turismo en los artículos publicados en revistas académicas de turismo. Estudios y Perspectivas en Turismo, 22 (5), pp. 875-892.

Badone, E. y Roseman, S. (eds.) (2004). Intersecting Journeys. The Anthropology of Pilgrimage and Tourism. Illionois, Estados Unidos: University of Illionois Press.

Barrientos, G. (2004a). El Cerrito Tepexpan: sustentador de vida. Un santuario indígena en el Valle de Ixtlahuaca. En J. Broda y C. Good (eds.), Historia y vida ceremonial en las comunidades mesoamericanas: los ritos agrícolas (pp. 351-372). Ciudad de México, México: Ediciones de la Universidad Nacional Autónoma de México.

Barrientos, G. (2004b). Otomíes. Pueblos indígenas del México Contemporáneo. Ciudad de México, México: Comisión Nacional para el Desarrollo de los Pueblos Indígenas.

Boullón, R. (1983). Las actividades turísticas y recreacionales: el hombre como protagonista. Ciudad de México, México: Trillas.

Cànoves, G. (2006). Turismo religioso en Montserrat: Montaña de fe, montaña de turismo. Cuadernos de Turismo, 18, pp. 63-76.

Cànoves, G. y Blanco, A. (2011). Turismo religioso en España: ¿La gallina de los huevos de oro? Una vieja tradición, versus un turismo emergente. Cuadernos de Turismo, (27) pp. 115-131.

Carmona, C. (2012). Fiesta del 12 de diciembre como principal detonador del turismo religioso en la Basilica de Guadalupe (Tesis de Licenciatura en Turismo). Universidad Autónoma del Estado de México. México, Toluca, Estado de México, México.

Cebrián, A. y García, R. (2014). Del turismo religioso a las peregrinaciones permanentes: Diversificación turística en el sureste español. CULTUR, (2), pp. 3-30.

Cohen, E. (1979). A phenomenology of tourism experience. Sociology, (132) , pp. 179-201.

Cohen, E. (1992). Pilgrimage centres: Concentric and excentric. Annals of Tourism Research, 19 (1), pp. 33-50.

Collins-Kreiner, N. (2010). Researching pilgrimage: Continuity and Transformations. Annals of Tourism Research, 37 (2), pp. 440-456.

Collins-Kreiner, N. y J.D. Gatrell, (2006). Tourism, heritage and pilgrimage: The case of Haifa's Baha'i gardens. Journal of Heritage Tourism, 1(1), pp. 32-50.

Collins-Kreiner, N. y N. Kliot, (2000). Pilgrimage tourism in the holy land: The behavioral characteristics of Christian pilgrims. GeoJournal, 501 (2,) pp. 55-67.

De la Cruz Clemente, P.S. (2010).Rituales agrícolas y de petición de Iluvia entre los otopanes en el Santuario del Señor del Cerrito, Estado de México (Tesis de Licenciatura en Historia). Universidad Autónoma del Estado de México, Toluca, Estado de México, México.

De Sousa, D. (1993). Tourism and pilgrimage: Tourist as Pilgrims? Contours, 6 (2), pp.4-8.

Durkheim, E. (2000). Las formas elementales de la vida religiosa. Ciudad de México, México: Colofón.

Eade, J. (1992). Pilgrimage and tourism at Lourdes, France. Annals of Tourism Research, 19 (1), pp. 18-32.

Eliade, M. (1998). Lo sagrado y lo profano. Barcelona, España: Paidós.

Esteve, R. (2002). Turismo y religión. Aproximación a la historia del turismo religioso. Málaga, España: Universidad de Málaga. 
Fernández, A.M. (2012). La Virgen de Talpa: religiosidad, turismo y sociedad. Política y Cultura, (38), pp. 29-48.

Graburn, N. (1977). Tourism: the sacred journey. En V. Smith (ed.), Hosts and guests: The anthropology of tourism (pp. 17-31). Filadelfia, Estados Unidos: University of Pennsylvania Press.

Gupta, V. (1999). Sustainable tourism: learning from Indian religious tradition. International Journey of Contemporary Hospitality Management, (2/3), pp.91-95.

Hernández González, M.I. (2013) La festividad del 3 de mayo en el Cerrito de Santa Cruz Tepexpan. Recuperado el 21 de marzo de 2014 de http://deas.inah.gob.mx/lafestividad-del-3-de-mayo-en-el-cerrito-de-santa-cruz-tepexpan/.

Hruleva, M., A. Blanco y G. Cànoves (2013). Monasterios en la ciudad de Sofía. Potencialidades del viaje de peregrinación y desarrollo turístico. Cuadernos de Turismo, (32), pp. 155-169.

Lanquar, R. (1985). Sociologie de tourisme et des voyages. París, Francia: Universitaires de France.

Lorenzo, L. y Ramón, F. (2011). La ruta de los sagrados corporales de Llutxent (Valencia) como una nueva expresión del turismo religioso en España. Estudios y Perspectivas en Turismo, 20 (4), pp. 960-971.

Maak, K. (2009). El Camino de Santiago como posible motor turístico en zonas rurales de escasos recursos: el caso de Brandeburgo. Cuadernos de Turismo, 23, pp. 149-171.

MacCanell, D. (1973). Staged authenticity: Arrangements of social space in tourist settings. American Journal of Sociology, (793), pp. 589-603.

Margry, P. J. (2008). Shrines and Pilgrimage in the Modern World. New Itineraries into the Sacred. Amsterdam, Países Bajos: Amsterdam University

Millán, M.G., E. Morales y L.M. Pérez (2010). Turismo religioso: estudio del Camino de Santiago. Gestión Turística, (13), pp. 9-37.

Mora, V. M., Serrano. R.C. y Osorio, M. (2017). El vínculo turismo-peregrinación. Un acercamiento desde la producción científica en inglés y en español. Estudios y Perspectivas en Turismo (1), pp. 86-106.

Nolan, M.L y S. Nolan (1992). Religious sites as tourism attractions in Europe. Annals of Tourism Research, 19 (1), pp. 68-78.

Olsen, D.H. y D.J Timothy (2006). Tourism and religious journeys. En D.J Timothy y D.H OIsen (eds.), Tourism, Religions and Spiritual Journeys (pp. 1-21). Nueva York, Estados Unidos: Routledge.

Osorio, M. (2005). El análisis del turismo desde la perspectiva de los sistemas funcionales. (Tesis de Doctorado en Ciencias Sociales). Universidad Iberoamericana. Ciudad de México, México.

Osorio, M. (2010). Turismo masivo y alternativo. Distinciones de la sociedad moderna/ posmoderna. Convergencia, 17 (52), pp. 235-259.

Puebla, J.J. (2011). Turismo religioso, el caso de San Juan de los Lagos. En R. Martínez (ed.), Turismo espiritual. Una alternativa de desarrollo para las poblaciones (pp. 63-76). Guadalajara, México: Universidad de Guadalajara,.

Raj, R. y N.D. Morphet (eds.) (2007). Religious Tourism and Pilgrimage Management: An International Perspective. Oxfordshire, Reino Unido: CABI. 
Rinschede, G. (1992). Forms of religious tourism. Annals of Tourism Research, 19 (1), pp. 51-67.

Shadow, R. y Rodríguez, M. (1994). La peregrinación religiosa en América Latina: enfoques y perspectivas. En C. Garma Navarro y R. Shadow (eds.) Las peregrinaciones religiosas: una aproximación (pp. 15-38). Ciudad de México, México: Universidad Autónoma Metropolitana.

Sharpley, R. (2009). Tourism, Religion and Spirituality. En T. Jamal y M. Robinson (eds.), The Sage Handbook of Tourism (pp. 237-253). Londres, Reino Unido: SAGE Publications.

Sharpley, R. y P. Sundaram (2005). Tourism: A sacred journey? The case of ashram tourism, India. International Journal of Tourism Research, 7, pp. 161-171.

Smith, V. (1992). Introduction: The quest in guest. Annals of Tourism Research, 19 (1), pp. 1-17.

Timothy, D.J. y D.H. Olsen (eds.) (2006). Tourism, Religion and Spiritual Journeys. Nueva York, Estados Unidos: Routledge.

Tobón, S.M. y N. Tobón (2013). Turismo religioso: fenómeno social y económico. Anuario Turismo y Sociedad, 14, pp. 237-249.

Turner, V. (1973). The center out there: Pilgrim's goal. History of Religions, (123), pp. 191230.

Turner, V. y Turner E. (1978). Image and Pilgrimage in Christian Culture: Anthropological Perspectives. Nueva York, Estados Unidos: Columbia University Press.

Williams, E., Francis, L., Robbins, M. y Annis, J. (2006). Visitor Experiences of St. David's Cathedral: The Two Worlds of Pilgrims and Secular Tourists. Documento presentado en The Tourism: The Spiritual Dimension Conference, Oxford, Reino Unido. 